\title{
Türk Mutfağında Bulunan Bazı Geleneksel Tatlı Türlerinin B Vitamini Kompozisyonlarının Belirlenmesi
}

\author{
Büşra Yusufoğlu ${ }^{1 *}$, Kübra Özkan ${ }^{2}$, Emine Karakuş ${ }^{1}$ \\ 1* Yıldız Teknik Üniversitesi, Fen Edebiyat Fakültesi, Kimya Bölümü, İstanbul, Türkiye, (ORCID: 0000-0002-9158-9732), yusufoglubusra@gmail.com \\ ${ }^{2}$ Sabahattin Zaim Üniversitesi, Sağlık Bilimleri Fakültesi, Beslenme ve Diyetetik Bölümü, İstanbul, Türkiye (ORCID: 0000-0002-7268-3571), \\ dyt.kubraozkann@gmail.com \\ ${ }^{1}$ Yıldız Teknik Üniversitesi, Fen Edebiyat Fakültesi, Kimya Bölümü, İstanbul, Türkiye (0000-0002-7730-3304), eminekaraku@gmail.com
}

(İlk Geliş Tarihi 2 Ekim 2020 ve Kabul Tarihi 16 Ocak 2021)

(DOI: 10.31590/ejosat.797273)

\begin{abstract}
ATIF/REFERENCE: Yusufoğlu, B., Özkan,, K. \& Karakuş, E. (2021). Türk Mutfağında Bulunan Bazı Geleneksel Tatlı Türlerinin B Vitamini Kompozisyonlarının Belirlenmesi. Avrupa Bilim ve Teknoloji Dergisi, (21), 241-246.
\end{abstract}

\section{Öz}

Bu çalışmada, laboratuvar koşullarında geleneksel servis usulüne göre hazırlanmış olan dört farklı geleneksel tatlı türünde bulunan bazı suda çözünen vitamin kompozisyonlarının miktarı belirlenmiştir. Çalışmada, $\mathrm{B}_{2}$ (riboflavin), nikotinik asit, nikotinamid, piridoksin (PN), piridoksal (PL) ve piridoksamin (PM) kompozisyonları miktarları Ters Fazlı - Yüksek Performanslı Sıvı Kromatografisi teknikleri kullanılarak (RP-HPLC) tespit edildi. B grubu vitamin kompozisyonlarının analizinde, HPLC cihazı, kapasite faktörü, seçicilik faktörü, çözünürlük faktörü gibi birçok kromatografik parametreye bağlı olduğu için en uygun ve en doğru analitik tekniklerden biridir. Çalışmada kullanılan örnekler; aşure, cevizli güllaç, kabak tatlısı, kadayıf dolmasıdır. Birçok ülkede geleneksel gıdaların besin kompozisyonları ile ilgili olarak yeterince bilgi bulunmamaktadır. Dolayısıyla, daha ileri çalışmalar gereklidir. Bu çalışmada, geleneksel tatlı türlerinde bulunan suda çözünen bazı vitaminlerin miktarlarını belirlemesi ve kaynak oluşturmaya katkı sağlaması açısından önemlidir. Çalışmada, B grubu vitaminlerinin analiz edilmesinin sebebi metabolizmada enerji üretiminin normal seviyelerde devam edebilmesinin B vitaminleri miktarına bağlı olmasından dolayıdır. Ayrıca, günlük diyetlerde B vitaminleri antioksidan özelliğine sahip olmakla beraber karbonhidrat metabolizmasında nikotinamin dinükleotit (NAD) ve flavinadenin dinükleotit (FAD) gibi koenzimlerin aktivitesinde önemli rol oynamaktadır. Çalışma sonucunda geleneksel tatlı türlerinin B vitamini kompozisyonları miktarları, en yüksek $\mathrm{B}_{1}$ vitamini $1917.4 \mu \mathrm{g}$ /porsiyon aşure, $\mathrm{B}_{2}$ vitamini $224.20 \mu \mathrm{g} /$ porsiyon kabak tatlıs1, $\mathrm{B}_{3}$ vitamini cevizli güllaç $3.4202 \mu \mathrm{g} / \mathrm{porsiyon}$ ve son olarak $\mathrm{B}_{6}$ vitamini $573.30 \mu \mathrm{g} /$ porsiyon kadayıf dolma olarak bulundu. Geleneksel tatlı türlerinin, bir porsiyonlarının günlük B grubu vitamin ihtiyacımızı karşılama oranları ise sırasıyla: aşure; $\mathrm{B}_{1} \% 164.5, \mathrm{~B}_{2} \% 9.49, \mathrm{~B}_{3} \% 8.12, \mathrm{~B}_{6} \% 23.8$, cevizli güllaç; $\mathrm{B}_{1} \% 6.05$, $\mathrm{B}_{2}$ $\% 10.3, \mathrm{~B}_{3} \% 8.39, \mathrm{~B}_{6} \% 12.4$, kabak tatlıs1; $\mathrm{B}_{1} \% 2.37, \mathrm{~B}_{2} \% 17.2, \mathrm{~B}_{3} \% 9.79, \mathrm{~B}_{6} \% 19.2$, kadayıf dolma; $\mathrm{B}_{1} \% 12.4, \mathrm{~B}_{2} \% 12.4, \mathrm{~B}_{3} \% 24.3$, $\mathrm{B}_{6} \% 43.9$ şeklinde bulundu.

Anahtar Kelimeler: Geleneksel tatlı türleri, Suda çözünen vitaminler, HPLC

\section{Determination of Vitamin B compositions of some Traditional Dessert Types in Turkish Cuisine}

\begin{abstract}
In this study, amount of some water solueble vitamin compositions were determined in four different traditional dessert types prepared in the laboratory conditions. In study, according to the traditional service method were determined using Reverse Phase - High Performance Liquid Chromatography techniques (RP-HPLC). In the analysis of group B vitamin compositions, HPLC techniques are one of the most appropriate and accurate analytical techniques, as they depend on many chromatographic parameters such as capacity factor, selectivity factor, solubility factor. Examples used in the study; asure, walnut rose, pumpkin dessert and kadayif stuffed. In many countries, there is not enough information related to nutritional composition of traditional foods. Therefore, further studies are required. In this study, it is important in terms of determining the amount of some water soluble vitamins found in traditional dessert types and contributing to source. In the study, the reason for analyzing the B group vitamins is that the energy production in metabolism can continue at normal levels and depends on the amount of B vitamins. In addition, although B vitamins have antioxidant properties in daily diets, they play an important role in the activity of coenzymes such as nicotinamine dinucleotide (NAD) and flavinadenin
\end{abstract}

*Sorumlu Yazar: yusufoglubusra@gmail.com 
dinucleotide (FAD) in carbohydrate metabolism. As a result of the study, the amount of composotions of vitamins B of traditional dessert types were found as the highest vitamin $\mathrm{B}_{1} 1917.4 \mu \mathrm{g} /$ portion asure, vitamin $\mathrm{B}_{2} 224.20 \mu \mathrm{g} /$ portion pumpkin dessert, vitamin $\mathrm{B}_{3}$ $3.4202 \mu \mathrm{g} /$ portion walnut rose and finally vitamin $\mathrm{B}_{6} 573.30 \mu \mathrm{g} /$ portion in kadayif stuffed. The ratios of one portion of traditional desserts to cover our daily vitamin $\mathrm{B}$ requirements were found respectively, asure $\mathrm{B}_{1} 164.5 \%, \mathrm{~B}_{2} 9.49 \%, \mathrm{~B}_{3} 8.12 \%, \mathrm{~B}_{6} 23.8 \%$, walnut rose; $\mathrm{B}_{1} 6.05 \%, \mathrm{~B} 210.3 \%, \mathrm{~B}_{3} 8.39 \%, \mathrm{~B}_{6} 12.4 \%$, pumpkin dessert; $\mathrm{B}_{1} 2.37 \%, \mathrm{~B}_{2} 17.2 \%, \mathrm{~B}_{3} 9.79 \%, \mathrm{~B}_{6} 19.2 \%$, kadayif stuffed; $\mathrm{B}_{1} 12.4 \%$, $\mathrm{B}_{2} 12.4 \%, \mathrm{~B}_{3} 24.3 \%, \mathrm{~B}_{6} 43.9 \%$.

Keywords: Traditional dessert types, Water-soluble vitamins, HPLC

\section{Giriş}

Türkiye; İran, Ortadoğu, Orta Asya, Bizans İmparatorluğu ve Osmanlı İmparatorluğu'nun Asya, Afrika ve Avrupa tarafindan yönetilen toprakları dahil olmak üzere birçok kültürden etkilenmiştir. On altıncı yüzyılın başlarından on dokuzuncu yüzyıla kadar etkisi büyük ölçüde doğudan batıya doğru ilerlediği için geleneksel yemek kültürü üzerinde, özellikle de Türk şekerleme ürünlerinde büyük etkileri olmuştur [1], [2]. Dolayısıyla geleneksel gıdalar nesilden nesile aktarılan bir mirası temsil etmektedir. Bu açıdan sürdürülmelerine katkı sağlanmalı ve besinsel kompozisyonlarının belirlenmesi de dahil olmak üzere ayrıntılı birçok dokümantasyon gereklidir [2].

Vitaminler, insan vücudunda metabolik faaliyetlerin çalışması için gerekli olan organik bileşikler grubudur. Kimyasal ve fizyolojik işlevleri çok çeşitlidir ve doğal gıda kaynaklarında yaygin olarak bulunurlar. İnsan beslenmesinde vitaminler çözünürlüklerine göre iki gruba ayrılabilir [3]. Çalışmamızda, tiamin, riboflavin, $\mathrm{B}_{3}$ nikotinik asit, nikotinamit, piridoksin, piridoksal, piridoksamin gibi suda çözünen B vitamini kompozisyonlarının miktarları analiz edilecektir.

Vitamin eksikliğinin, kardiyovasküler rahatsızlıklar ve kronik böbrek rahatsızlığı üzerine etkisinin incelendiği bir çalışmada $\mathrm{B}_{6}$ vitaminin alınmasının kronik böbrek rahatsızlığına sahip olan kişilerde olumlu etkilere sahip olduğu belirtilmiştir [4]. Bunun dışında, $B_{6}$ vitaminlerinin bazı vitamerleri ve $B_{1}$ vitaminlerinin aminoguanidine kıyasla endojen glikasyon ürünlerinin oluşumunu daha çok kısıtladığ vitamini (niasin), gidalarda nikotinik asit $\left(\mathrm{C}_{6} \mathrm{H}_{5} \mathrm{NO}_{2}\right)$ ve nikotinamid $\left(\mathrm{C}_{6} \mathrm{H}_{6} \mathrm{~N}_{2} \mathrm{O}\right)$ olarak bulunan suda çözünen önemli vitaminlerden biridir. Niasin, biyosentez ve enerji üretimi gibi birçok önemli biyolojik fonksiyona sahiptir [6]. Riboflavin, koenzim olan flavin mononükleotit (FMN) ve flavin adenin dinükleotidi (FAD) gibi formların yapısına katılır. Enerji metabolizmasında, oksidasyon ve indirgeme reaksiyonlarında rol oynar [7]. Riboflavin eksikliği, flavin koenzim aktivitesini azaltır ve demir emilimine müdahale ederek anemi, kanser ve kardiyovasküler rahatsızlıkların oluşmasına neden olur. Özellikle folat ve $\mathrm{B}_{6}$ vitamini miktarı, riboflavin miktarına bağlı olarak azalabilmektedir [8].

Geleneksel gıdaların incelenmesi, diyet tarzı ve bunların zaman içinde nasıl şekillendiğine dair önemli bir fikir sunar. Geleneksel yiyecekler zaman içinde test edilmiş potansiyel sağlık özelliklerine sahip olabilir. $\mathrm{Bu}$ nedenle, halkın beslenme ve sağlıklı beslenme konusundaki mevcut ilgisi, geleneksel gidalara olan talebin artmasına katkıda bulunmuştur [9].

\section{Materyal ve Metot}

\section{1. Çalışmada Kullanılan Örnekler}

Bu çalışma da kullanılan dört farklı geleneksel tatlı türü için gerekli tüm malzemeler İstanbul, Türkiye'de bulunan marketlerden satın alınarak geleneksel servis usulüne uygun bir şekilde hassas terazi ile tartılarak İstanbul Sabahattin Zaim Üniversitesi Beslenme Laboratuvarı'nda hazırlandı. Her bir örnek için porsiyon miktarı ayrı ayrı tartılarak belirlenmiştir sırasıyla; aşure, cevizli güllaç, kabak tatlısı, kadayıf dolma için sırasıyla 301 g, 220 g, 190 g, 245 g şeklindedir.

\subsubsection{Materyal}

$\mathrm{Bu}$ makalede kullanılan çözeltiler analitik saflıkta, günlük olarak hazırlandı. Hidroklorik asit çözeltisi, taka diastaz, ortofosforik asit ve potasyum ferrisiyanid çözeltisi (\%1) Sigma Chem. Co. (St. Louis, MO), sodyum hidroksit çözeltisi FlukaAnalytical, sodyum asetat çözeltisi (2.5 M) Isolabchemicals marka satın alınd1. Su aritma sistemi (Direct-Q3 UV) ile damıtılmış su ile hazırlandı. Deney sırasında HPLC Shimadzu marka Nexera-i LC - 2040C 3D tip (Shimadzu Corp., Japonya), çalkalamalı su banyosu (Memmert GmbH + Co.KG, Almanya), buzdolabı (Uğur Soğutma Makinaları, Türkiye), öğütücü (Sinbo), hassas terazi (Radwag - AS 220.R2, Radwag Terazileri ve Terazileri, Polonya), otomatik pipetler (100 / 1000 $\mu 1-5 / 50 \mu 1-2 /$ 200 $\mu 1$ ), (Axypet - Otoklavlanabilir, Merck Almanya), ultrasonik su banyosu (Selecta Ultrasons HD, JP SELECTA SA İspanya), 0.45 um CA filtresi (Chromafil CA-45/25) kullanıldı.

\subsubsection{Metod}

$\mathrm{Bu}$ çalışma da sırasıyla; $\mathrm{B}_{1}, \mathrm{~B}_{2}, \mathrm{~B}_{3}$ ve $\mathrm{B} 6$ vitamin kompozisyonları her bir örnek için farklı metodlar modifiye edildi [10], [11], [12]. Tüm örnekler için, stok çözeltisini çözmek için $0.1 \mathrm{~N}$ hidroklorik asit çözeltisi hazırlandı. Çalışma sırasında kullanılan her bir standard çözeltisi günlük olarak, analiz için hazırlandı. Daha sonra Şekil 1.'deki modifiye yöntem sırasıyla kullanıldı. Örnekler hazırlandıktan sonra, $\mathrm{B}_{1}, \mathrm{~B}_{2}$ ve $\mathrm{B} 6$ vitamini analizi Shimadzu Nexera-i LC - 2040C 3D (Shimadzu Corporation, Kyoto, Japan) marka HPLC cihazında yapıldı. Mobil faz distile su ve asetonitril ile (85:15) hazırlandi. Floresans dedektörde, eksitasyon dalga boyu ve emisyon dalga boyu

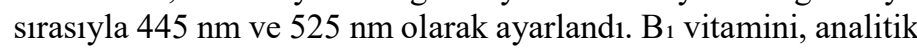

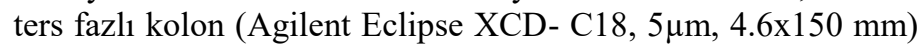
ile $1 \mathrm{~mL}$ /dakika akış hızıyla ayrıldı. Farklı olarak B3 vitaminin analizi sirasında eksitasyon dalga boyu ve emisyon dalga boyu sirasıyla $322 \mathrm{~nm}$ ve $380 \mathrm{~nm}$ olarak ayarland1. 
$B_{1}$ Vitamini

Homojenize edilmiş $10 \mathrm{~g}$ örnek erlen içerisinde tartıld1, üzerine 60 $\mathrm{mL}, 0.1 \mathrm{~N}$ hidroklorik çözeltisi ilave edildi. Daha sonra $121^{\circ} \mathrm{C}^{\prime}$ 'de 30 $\mathrm{dk}$ otoklavland1. Örnekler oda sıcaklığına kadar soğutuldu. $2.5 \mathrm{M}$ sodyum asetat çözeltisi ile $\mathrm{pH} 4.5$ yapilmıștır. Örneğin üzerine $100 \mathrm{mg}$ takadiastaz ve $5 \mathrm{mg}$ asit fosfataz ilave edildikten sonra çalkalamalı su banyosunda $45^{\circ} \mathrm{C}^{\prime}$ de 3 saat süre ile inkübe edildi. Süre sonunda oda sicaklığına gelene kadar soğutuldu ve hacim 100 $\mathrm{mL}$ olacak şekilde $0.1 \mathrm{~N} \mathrm{HCI}$ çözeltisi ile tamamlandiktan sonra adi filtre kağı̀ından süzüldükten sonra $0.45 \mu \mathrm{m}$ filtreden süzülerek HPLC cihazına enjekte edildi.

\section{$\mathrm{B}_{2}$ vitamini}

Homojenize edilmiş $10 \mathrm{~g}$ örnek erlen içerisinde tartıld1, üzerine $60 \mathrm{~mL} 0.1 \mathrm{~N}$ hidroklorik çözeltisi ilave edildi. $121^{\circ} \mathrm{C}^{\prime}$ de $30 \mathrm{dk}$ otoklavlandindiktan sonra örnekler oda sıcaklığına kadar soğutuldu ve $2.5 \mathrm{M}$ sodyum asetat çözeltisi kullanılarak pH 4.5 yapıldı. Örneğin üzerine $100 \mathrm{mg}$ takadiastaz, $5 \mathrm{mg}$ asit fosfataz, $1 \mathrm{mg}$ distile su ilave edildi.

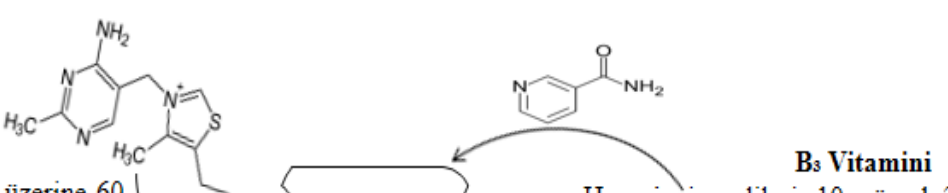

Homojenize edilmiş $10 \mathrm{~g}$ örnek $250 \mathrm{~mL}$ 'lik erlene konularak tartıld1, üzerine $60 \mathrm{~mL} 0.1 \mathrm{~N}$ hidroklorik asit ilave edildikten sonra $121^{\circ} \mathrm{C}$ 'de $30 \mathrm{dk}$ otoklavland1 ve daha sonra örnekler oda sicaklığına gelinceye kadar soğutuldu. Son hacim $0.1 \mathrm{~N}$ hidroklorik asitle tamamlandiktan sonra adi filtre kağıgdından süzülerek $0.45 \mu \mathrm{m}$ filtreden geçirildi ve HPLC cihazına enjekte edildi.

Şekil 1. $B_{1}, B_{2}, B_{3}$ ve $B_{6}$ Vitaminlerinin Analizi

\section{Araştırma Sonuçları ve Tartışma}

\subsection{Tatlı Türlerinde Bulunan $B_{1}, B_{2}, B_{3}$ ve $B_{6}$ Vitamin Miktarları}

$\mathrm{Bu}$ çalışmada dört çeşit aşure, kadayıf dolması, cevizli güllaç, kabak tatlısı gibi geleneksel tatlı türlerinin, tiamin, riboflavin, nikotinik asit, nikotinamid, piridoksin, piridoksal ve piridoksamin miktarlarını belirlendi.

$\mathrm{Bu}$ çalışmada, bazı geleneksel tatlı türlerinde bulunan $\mathrm{B}_{1}$ vitamini kompozisyonları Tablo 1'de verilmiştir. En yüksek B vitaminine sahip geleneksel tatlı türü aşuredir. 1 porsiyon aşure içerisinde $1917.4 \mu \mathrm{g}$ /porsiyon $\mathrm{B}_{1}$ vitamini vardır. Biyoerişebilirlik açısından değerlendirildiğinde aşurenin $\mathrm{B}_{1}$ vitamini sindirilebilirliği en yüksektir (Tablo 1.).

Tablo 2'de bazı geleneksel tatlı türlerinde bulunan $\mathrm{B}_{2}$ vitamini kompozisyonları verilmiştir. En yüksek $B_{2}$ vitaminine sahip geleneksel tatlı türü kabak tatlısıdır. 1 porsiyon kabak tatlısı içerisinde $224.20 \mu \mathrm{g}$ /porsiyon $\mathrm{B}_{2}$ vitamini vardır. Biyoerişebilirlik açısından değerlendirildiğinde kabak tatlısının sindirilebilirliği en yüksektir (Tablo 2.).

Bazı geleneksel tatlı türlerinde bulunan $\mathrm{B}_{3}$ vitamini kompozisyonları Tablo 3'de verilmiştir.
En yüksek $B_{3}$ vitaminine sahip geleneksel tatlı türü kadayıf dolmadır. 1 porsiyon kadayıf dolma içerisinde 3.4202 $\mu \mathrm{g} /$ porsiyon $\mathrm{B}_{3}$ vitamini vardır. Biyoerişebilirlik açısından değerlendirildiğinde kadayıf dolma sindirilebilirliği en yüksektir (Tablo 3).

Bazı geleneksel tatlı türlerinde bulunan $\mathrm{B}_{6}$ vitaminin pyridoksin (PN), piridoksal (PL) ve piridoksamin (PM) gibi kompozisyonları ve toplam B 6 miktarı Tablo 4'de verilmiştir. En yüksek $B_{6}$ vitaminine sahip geleneksel tatlı türü kadayıf dolmadır. 1 porsiyon kadayıf dolma içerisinde $573.30 \mu \mathrm{g} /$ porsiyon $\mathrm{B}_{6}$ vitamini vardır. Biyoerişebilirlik açısından değerlendirildiğinde kabak tatlısının sindirilebilirliği en yüksektir (Tablo 4.).

$\mathrm{Bu}$ çalışmada şeker içeriğine sahip tatlı türlerinin 1 porsiyonlarının günlük $\mathrm{B}$ grubu vitamin ihtiyacımızı karşılama oranları sırasıyla: aşure; $\mathrm{B}_{1} \% 164.5, \mathrm{~B}_{2} \% 9.49, \mathrm{~B}_{3} \% 8.12, \mathrm{~B}_{6}$ $\% 23.8$, cevizli güllaç; $\mathrm{B}_{1} \% 6.05, \mathrm{~B}_{2} \% 10.3, \mathrm{~B}_{3} \% 8.39, \mathrm{~B}_{6} \% 12.4$, kabak tatlis1; $\mathrm{B}_{1} \% 2.37, \mathrm{~B}_{2} \% 17.2, \mathrm{~B}_{3} \% 9.79, \mathrm{~B}_{6} \% 19.2$, kadayif dolma; $\mathrm{B}_{1} \% 12.4, \mathrm{~B}_{2} \% 12.4, \mathrm{~B}_{3} \% 24.3, \mathrm{~B}_{6} \% 43.9$ şeklinde bulunmuştur. 
Tablo 1. Bazı Geleneksel Tatlı Türlerinde Bulunan B Vitamini Miktarlarl

\begin{tabular}{lccc}
\hline Örnekler & $\boldsymbol{\mu g} / \mathbf{1 0 0 g}$ & $\boldsymbol{\mu g} / \mathbf{p o r s i y o n}$ & $\boldsymbol{\mu g} / \mathbf{o}$ \\
\hline Aşure & $634.9 \pm 28.7$ & $1917.4^{\mathrm{a}}$ & 164.5 \\
\hline Cevizli Güllaç & $32.9 \pm 1.5$ & $72.600^{\mathrm{b}}$ & 6.05 \\
\hline Kabak Tatlısı & $15.0 \pm 0.7$ & $28.500^{\mathrm{b}}$ & 2.37 \\
\hline Kadayıff Dolma & $60.8 \pm 2.8$ & $149.45^{\mathrm{b}}$ & 12.4 \\
\hline
\end{tabular}

Tablo 2. Bazı Geleneksel Tatlı Türlerinde Bulunan B2 Vitamini Miktarları

\begin{tabular}{lccc}
\hline Örnekler & $\boldsymbol{\mu g} / \mathbf{1 0 0 g}$ & $\boldsymbol{\mu g} / \mathbf{p o r t i o n}$ & $\boldsymbol{\mu g} / \mathbf{o}$ \\
\hline Aşure & $40.9 \pm 1.8$ & $123.41^{\mathrm{a}}$ & 9.49 \\
\hline Cevizli Güllaç & $60.8 \pm 2.8$ & $134.20^{\mathrm{a}}$ & 10.3 \\
\hline Kabak Tatlısı & $117.6 \pm 5.3$ & $224.20^{\mathrm{a}}$ & 17.2 \\
\hline Kadaylf Dolma & $65.8 \pm 3.0$ & $161.70^{\mathrm{a}}$ & 12.4 \\
\hline
\end{tabular}

Tablo 3. Bazı Geleneksel Tatlı Türlerinde Bulunan B 3 Vitamini Miktarları

\begin{tabular}{lccccc}
\hline Örnekler & $\begin{array}{c}\text { Nikotinik asit } \\
\boldsymbol{\mu g} / \mathbf{1 0 0 g}\end{array}$ & Nikotinamid & $\begin{array}{c}\text { Toplam } \mathbf{B}_{\mathbf{3}} \\
\mathbf{v i t a m i n i} \\
\boldsymbol{\mu g} / \mathbf{1 0 0 g}\end{array}$ & $\begin{array}{c}\boldsymbol{\mu g} / \\
\text { porsiyon }\end{array}$ & $\mathbf{\mu / \%}$ \\
\hline Aşure & $217.3 \pm 9.8$ & $160.5 \pm 7.3$ & 379.00 & $1.1408^{\mathrm{b}}$ & 8.12 \\
\hline Cevizli Güllaç & $187.4 \pm 8.5$ & $346.8 \pm 15.7$ & 536.00 & $1.1792^{\mathrm{b}}$ & 8.39 \\
\hline Kabak Tatllsı & $490.4 \pm 22.2$ & $231.2 \pm 10.5$ & 724.00 & $1.3756^{\mathrm{b}}$ & 9.79 \\
\hline Kadayıf Dolma & $1004.6 \pm 45.5$ & $386.7 \pm 17.5$ & 1396.0 & $3.4202^{\mathrm{a}}$ & 24.3
\end{tabular}

Tablo 4. Bazı Geleneksel Tatlı Türlerinde Bulunan B 6 Vitamini Miktarları

\begin{tabular}{lcccccc}
\hline Örnekler & $\begin{array}{c}\text { PL } \\
\boldsymbol{\mu g} / \mathbf{1 0 0 g}\end{array}$ & $\begin{array}{c}\mathbf{P N} \\
\boldsymbol{\mu g} / \mathbf{1 0 0 g}\end{array}$ & $\begin{array}{c}\mathbf{P M} \\
\boldsymbol{\mu g} / \mathbf{1 0 0 g}\end{array}$ & $\begin{array}{c}\text { Toplam } \mathbf{B}_{\mathbf{6}} \\
\mathbf{v i t a m i n i} \\
\boldsymbol{\mu g} / \mathbf{1 0 0 g}\end{array}$ & $\boldsymbol{\mu g} / \mathbf{p o r s i y o n}$ & $\boldsymbol{\mu g} / \mathbf{\%}$ \\
\hline Aşure & $18.9 \pm 0.9$ & $23.9 \pm 1.1$ & $60.4 \pm 3.6$ & 103.0 & $310.03^{\mathrm{ab}}$ & 23.8 \\
\hline Cevizli Güllaç & $43.9 \pm 2.0$ & $7.0 \pm 0.3$ & $22.9 \pm 1.0$ & 74.00 & $162.80^{\mathrm{b}}$ & 12.4 \\
\hline Kabak Tatlisı & $95.7 \pm 4.3$ & $26.9 \pm 1.2$ & $9.0 \pm 0.4$ & 132.0 & $250.80^{\mathrm{ab}}$ & 19.2 \\
\hline Kadayıf Dolma & $173.4 \pm 7.8$ & $31.9 \pm 1.4$ & $27.9 \pm 1.3$ & 234.0 & $573.30^{\mathrm{a}}$ & 43.9 \\
\hline
\end{tabular}




\subsection{Tartışma}

Bu çalışmada tiamin, riboflavin, nikotinik asit, nikotinamid, piridoksin veya piridoksol ve piridoksamin gibi vitamin kompozisyonlarının miktarı, dört çeşit örnek olarak kullanılan aşure, cevizli güllaç, kabak tatlısı, kadayıf dolması kullanılarak belirlendi.

Türk Gıda Veri Kompozisyonu Veri Tabanı'na göre; Ankara'dan temin edilen bir aşure içerisinde tiamin 0.030 $\mathrm{mg} / 100 \mathrm{~g}$, riboflavin $0.019 \mathrm{mg} / 100 \mathrm{~g}$, niasin eşdeğerleri toplamı $1.632 \mathrm{mg} / 100 \mathrm{~g}$ şeklindedir. Hamsiköy, Trabzon'a özgü bir güllaç tatlısında, tiamin $0.028 \mathrm{mg} / 100 \mathrm{~g}$, riboflavin $0.188 \mathrm{mg} / 100 \mathrm{~g}$, niasin eşdeğerleri toplamı $0.028 \mathrm{mg} / 100 \mathrm{~g}$ şeklinde bulunmuştur. İstanbul'da bulunan bir güllaç örneğinde; tiamin $0.020 \mathrm{mg} / 100 \mathrm{~g}$, riboflavin $0.009 \mathrm{mg} / 100 \mathrm{~g}$, niasin eşdeğerleri toplamı 0.000 $\mathrm{mg} / 100 \mathrm{~g}$ şeklindedir [13].

Çatak ve Yaman (2019)'da yılında yaptıkları çalışmada, İstanbul, Türkiye'ye ait toplam 67 meyve ve sebzenin nikotinik asit ve nikotinamid içeriklerini post-kolon türevlendirme sistemi kullanılarak HPLC ile belirlemiştir. Bu çalışma gerek örnek kapsamı gerek analiz edilen vitamin türleri açısından yapılan en kapsamlı çalışmadır. Çalışmada kabak örneğinde nikotinikasit $0.741 \mathrm{mg} / 100 \mathrm{~g}$, nikotinamid $0.223 \mathrm{mg} / 100 \mathrm{~g}$, total $\mathrm{B}_{3}$ vitamini miktarı $0.964 \mathrm{mg} / 100 \mathrm{~g}$ şeklinde bulunmuştur [6].

Petteys ve Frank (2010)'da B $B_{2}$ vitamini (riboflavin) HPLC ile plazmada florometrik yöntemle hızlı bir şekilde tespit edilmiştir. $\mathrm{Bu}$ çalışma da riboflavinin 7 dakika içinde ayrılmasını ve ölçülmesini sağlanmıştır. Örnek olarak proteinler asit çökeltme ile plazmadan uzaklaştırılmıştır. Elde edilen süpernatantın bir örneği ters fazlı HPLC ile analiz edilmiştir [7].

Gliszczyńska-Świgło ve Rybicka (2015)'da yaptıkları çalışma da, 13 farklı enerji içeceğinde kafein ve suda çözünen vitaminlerin miktarlarını $30 \mathrm{dk}$ içerisinde yüksek performanslı sıv1 kromatografisi (HPLC) yöntemini kullanarak fotodiyot dizisi ve floresan tespiti eş zamanlı olarak tespit etmişlerdir. $\mathrm{Bu}$ yöntemin, enerji içeceklerinde suda çözünen vitamin takviyeleri ve kafeinin, kantitatif analizinde faydalı olabileceğini göstermişlerdir [14].

Ekinci (2014)'da geleneksel bir Türk tahıl gıdası olan tarhanada bulunan suda çözünür vitaminlerin miktarının fermantasyon ve kurutma yöntemleri sırasında sıcaklığın ne derece önemli olduğunu incelemiştir. Çalışmanın sonucunda, iki yönteminde sıcaklığa bağlı olarak vitamin konsantrasyonları üzerinde önemli etkilere sahip olduğunu göstermiştir. Fermentasyonun, tarhananın suda çözünür vitamin içeriği üzerinde artan bir etkisi olduğu, kurutmanın ise azalan bir etkisi olduğu sonucuna varılmıştır [15].

Pandian ve Jayalakshmi (2019)'da Psidium guajava adlı bitkinin yapraklarında bulunan suda çözünür B vitamin miktarlarını belirlemişlerdir. Çalışmada, tiamin $0.213 \mu \mathrm{g} / \mathrm{g}$, riboflavin $0.325 \mu \mathrm{g} / \mathrm{g}$ niasin $0.002 \mu \mathrm{g} / \mathrm{g}$, piridoksin $0.002 \mu \mathrm{g} /$ olarak bulunmuştur. $\mathrm{Bu}$ çalışmanın amacı gelişmekte olan ülkelerde yaşayan ve B vitamini eksikliği yaşayan bireylere, yumurta, et, balık gibi B vitaminleri açısından zengin gıdalara ulaşamadıkları için, alternatif kaynak sunmaktır [16].

Yusufoğlu vd. (2019)'da yaptıkları çalışmada; bazı geleneksel gıdaların B vitaminleri kompozisyonlarının miktarını analiz etmişlerdir. Çalışma da analiz edilen örnekler sırasıyla, mercimek köftesinde $\mathrm{B}_{1}$ vitamini $299.20 \mu \mathrm{g} /$ porsiyon, $\mathrm{B}_{2}$ vitamini $364.32 \mu \mathrm{g}$ /porsiyon yine mercimek köftesi, daha sonra $\mathrm{B}_{3}$ vitamini için zeytinyağlı yaprak sarma $1030.4 \mu \mathrm{g} /$ porsiyon ve son olarak B 6 vitaminin $281.0 \mu \mathrm{g} /$ porsiyon olarak lahmacunda analiz edilmiştir [17].

$\mathrm{Bu}$ çalışmada kullanılan dört farklı geleneksel tatlı türleri sırasıyla; aşure, cevizli güllaç, kabak tatlısı ve kadayıf dolma şeklindedir. Aşure; Türkiye'deki neredeyse tüm etnik, dini ve kültürel toplulukların mutfak geleneğinin paylaştığı kuru meyveler, fındık ve tahıllar gibi çok çeşitli malzemeler kullanılarak bir metafor olarak Nuh'un pudingi olarak adlandırılan lezzetli bir tatlıdır [18]. Aşure tatlısı; tahıl ve kurubaklagil, cevizli güllaç süt ve taze meyveler, kabak tatlısı, kabak ve bazı kuruyemişler ve son olarak kadayıf dolması hamur içeriğine sahiptir [1], [19]. Türk mutfağında yapılan tatlı çeşitlerinden enerji ve besin değerleri açısından sütlü tatlı çeşitleri tüketim açısından en dengeli olanlardır. Sütlü tatlı çeşitleri kalsiyum ve $\mathrm{B}_{2}$ vitamininden zengindirler. Bu çalışmada sütlü tatlı örneği olarak cevizli güllaç kullanılmıştır. Protein, kalsiyum ve B vitaminleri açısından zengindir, ayrıca mevsiminde kullanılan ve herhangi bir işlem görmeyen meyveler kullanılması bakımından diğer tatlılara oranla sindirimi daha kolay ve sağlıklı bir tatlıdır. Aşure tatlısı bol miktarda tahıl, kurubaklagil ve meyve içermesi sebebiyle B vitamin gruplarınca zengin bulundu. Kabak tatlısı, Orta Amerika'da doğduğuna inanılan yiyecek ve ilaç yapımında kullanılan kabak ile yapılır yumuşak ve tatlı olması, yüksek besin değerine sahip olması ve $\beta$-karoten, lutein ve zeaksantin gibi özellikle mükemmel bir karotenoid kaynağı olması açısından önemli bir besin kaynağıdır. En son olarak, Balkanlar, Türkiye ve Ortadoğu ülkelerinde on sekizinci yüzyıl Türk tatlılarının en lezzetli çeşidi kadayıf dolması gibi hamur tatlılarının enerji değerinin yüksek olduğu bulunmuştur [1], [20]. [21].

\section{Sonuç}

Gıdaların Gıdaların farklı bölgelerden temin edilerek analiz edilmesi ve bu şekilde gıda kompozisyonu tablolarının; miktar, kalite açısından genişletilmesi ve iyileştirilmesi gerekmektedir. $\mathrm{Bu}$ açıdan çalışmamız tiamin, riboflavin, nikotinik asit, nikotinamid, piridoksin veya piridoksol ve piridoksaminin geleneksel şeker içerikli gıdalarda var olan miktarlarını analiz ederek kamuoyuna kaynak sunmuştur. Çalışma ayrıca, beslenme uzmanları tarafindan diyet hazırlanması, beslenme eğitimi, gıda güvenliği, gıda endüstrisindeki gıdaların etiketlenmesi, beslenme araştırması ve diğer araştırma amaçları içinde referans oluşturacaktır. Çalışmada kullanılan örneklerden aşure; çeşitli baklagillerin, kuru meyvelerin ve bazı yağlı tohumların kullanılarak hazırlanmasıyla oluşan hem $\mathrm{B}_{1}$ vitamini hem de proteini oluşturan aminoasitler açısından diğer geleneksel tatlı türlerine göre daha yüksek düzeydedir. Bu sebeple beslenme uzmanları kontrollü tüketim koşuluyla oldukça sağlıklı bir tatlı alternatifi olarak sunabilirler. Çalışmamızda kullanılan bir diğer geleneksel tatlı türü olan kabak tatlısı analiz sonucunda $\mathrm{B}_{2}$ vitamini açısından yüksektir. Bunun dışında kabak hem $\mathrm{A}, \mathrm{C}$ ve $\mathrm{K}$ vitaminleri hem de $\mathrm{Na}^{+}, \mathrm{K}^{+}, \mathrm{Ca}^{+2}$ ve $\mathrm{Mg}^{+2}$ gibi mineraller açısından zengin olup yüksek miktarda su içermesinden dolayı şerbetli tatlılara göre kalorisi nispeten daha düşüktür. Çalışmada kullanılan bir diğer örnek olan kadayıf dolmasının $\mathrm{B}_{3}$ ve $\mathrm{B}_{6}$ vitamin düzeylerinin yüksek olması ceviz ve yumurta kullanımına bağlı olduğu öngörülmüştür. Son olarak kullanılan cevizli güllaç 
örneği; $B_{1}, B_{2}, B_{3}$ ve $B_{6}$ vitaminleri açısından yüksek olmayıp protein ve $\mathrm{Ca}^{+2}$ açısından Türk mutfağında bulunan oldukça zengin geleneksel bir tatlı alternatifi olarak karşımıza çıkmaktadır.

\section{Kaynakça}

[1] Işın, M. (2013). Sherbet\& Spice The Complete Story of Turkish Sweets and Desserts.2-11

[2] Vasilopoulou, E., Dilis, V., \& Trichopoulou, A. (2013). Nutrition claims: a potentially important tool for the endorsement of Greek Mediterranean traditional foods. Mediterranean Journal of Nutrition and Metabolism, 6(2), 105-111.

[3] Ball, G. F. (2005). Vitamins in foods: analysis, bioavailability, and stability. CRC Press.

[4] Busch, M., Göbert, A., Franke, S., Ott, U., Gerth, J., Müller, A., \& Wolf, G. (2010). Vitamin B6 metabolism in chronic kidney disease-relation to transsulfuration, advanced glycation and cardiovascular disease. Nephron Clinical Practice, 114, c38-c46. doi: 10.1159/000245068.aynaklar

[5] Booth, A. A., Khalifah, R. G., \& Hudson, B. G. (1996). Thiamine pyrophosphate and pyridoxamine inhibit the formation of antigenic advanced glycation end-products: comparison with aminoguanidine. Biochemical and Biophysical Research Communications, 220, 113-119. doi: 10.1006/bbrc. 1996.0366

[6] Çatak, J., \& Yaman, M. (2019). Research Article Determination of Nicotinic Acid and Nicotinamide Forms of Vitamin B3 (Niacin) in Fruits and Vegetables by HPLC Using Postcolumn Derivatization System.

[7] Petteys, B. J., \& Frank, E. L. (2011). Rapid determination of vitamin B2 (riboflavin) in plasma by HPLC. Clinica Chimica Acta, 412(1-2), 38-43.

[8] Powers, H. J. (2003). Riboflavin (vitamin B-2) and health. The American journal of clinical nutrition, 77(6), 1352-1360.

[9] Trichopoulou, A., Soukara, S., \& Vasilopoulou, E. (2007). Traditional foods: a science and society perspective. Trends in Food Science \& Technology, 18(8), 420-427.

[10] Esteve, M. J., Farré, R., Frígola, A., García-Cantabella, J. M. 2001. Simultaneous determination of thiamin and riboflavin in mushrooms by liquid chromatography. Journal of Agricultural and Food Chemistry, 49(3), 1450-1454.

[11] Ndaw, S., Bergaentzle, M., Aoudé-Werner, D., Hasselmann, C. 2002. Enzymatic extraction procedure for the liquid chromatographic determination of niacin in foodstuffs. Food Chemistry, 78(1), 129-134.

[12] Sampson DA, Eoff LA, Yan XL, Lorenz K. Analysis of free and glycosylated vitamin B6 in wheat by high-performance liquid chromatography. Cereal Chemistry; 1995, 72(2),217220.

[13]Ulusal Gida Kompozisyon Veri Taban1, http://www.turkomp.gov.tr/main, Erişim Tarihi:24.02.2020
[14] Gliszczyniska-Swigho, A., Rybicka, I. (2015) Simultaneous determination of caffeine and water-soluble vitamins in energy drinks by HPLC with photodiode array and fluorescence detection. Food analytical methods, 8(1), $139-146$

[15] Ekinci, R. (2005). The effect of fermentation and drying on the water-soluble vitamin content of tarhana, a traditional Turkish cereal food. Food chemistry, 90(1-2), 127-132.

[16] Pandian, R. S., \& Jayalakshmi, M. (2019). HPLC analysis of water soluble vitamin $\mathrm{B}$ in leaves Psidium guava. Asian Journal of Pharmacy and Pharmacology, 5(1), 69-72.

[17] Yusufoğlu, B., Dumanlı, K., Yaman, M. \& Karakuş, E. (2019). Dünyanın En İyi Varış Noktası Türk Mutfağına Biyokimyasal Bakıș: Bazı Geleneksel Yemekler ve B Vitamini Kompozisyonları. Avrupa Bilim ve Teknoloji Dergisi, (16), 874-880.

[18] Food and Culture History Society Communication di Giovanna Motta Volume secondo 2017 page 260261

[19] Stuart, M.E., All About Pumpkins, (October 2004). The University of Arizona

[20] Song, J., Wang, X., Li, D., Meng, L., \& Liu, C. (2017). Degradation of carotenoids in pumpkin (Cucurbita maxima L.) slices as influenced by microwave vacuum drying. International Journal of Food Properties, 20(7), 1479-1487.

[21] Ertaş, Y.\& Gezmen, M. (2013). Sağlıklı Beslenmede Türk Mutfak Kültürünün Yeri. Gümüşhane Üniversitesi Sağlık Bilimleri Dergisi 2(1):117-136. 